\title{
Preparation of Poly(silylene- $p$-phenylene)s Bearing a Benzocrown Pendant Group and Their Iono- and Solvatochromic Behavior in the Emission Spectra
}

Joji Ohshita,* Taisuke Uemura, Takahiro Inoue, Koichi Hino, Atsutaka Kunai*

Department of Applied Chemistry, Graduate School of Engineering, Hiroshima University, Higashi-Hiroshima 739-8527, Japan

\section{Supporting Information}

${ }^{1} \mathrm{H}$ NMR spectra of polymers $\mathbf{1}, \mathbf{2 c}$, and $\mathbf{3}$ in $\mathrm{CDCl}_{3}$, and EDS data for the ash obtained by combustion of polymer 2a. The NMR spectra were recorded on a JEOL model EX-270 spectrometer. EDS data was measured on a JEOL model JSM-6390LA SEM.

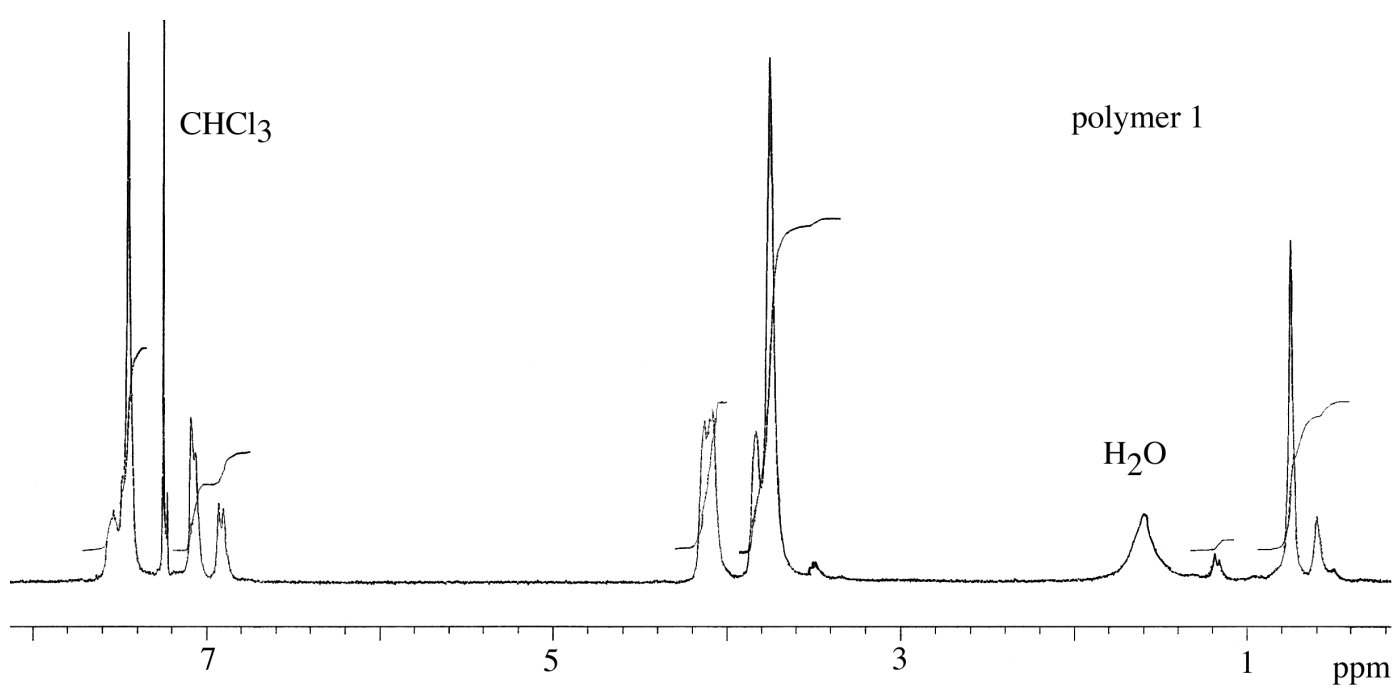



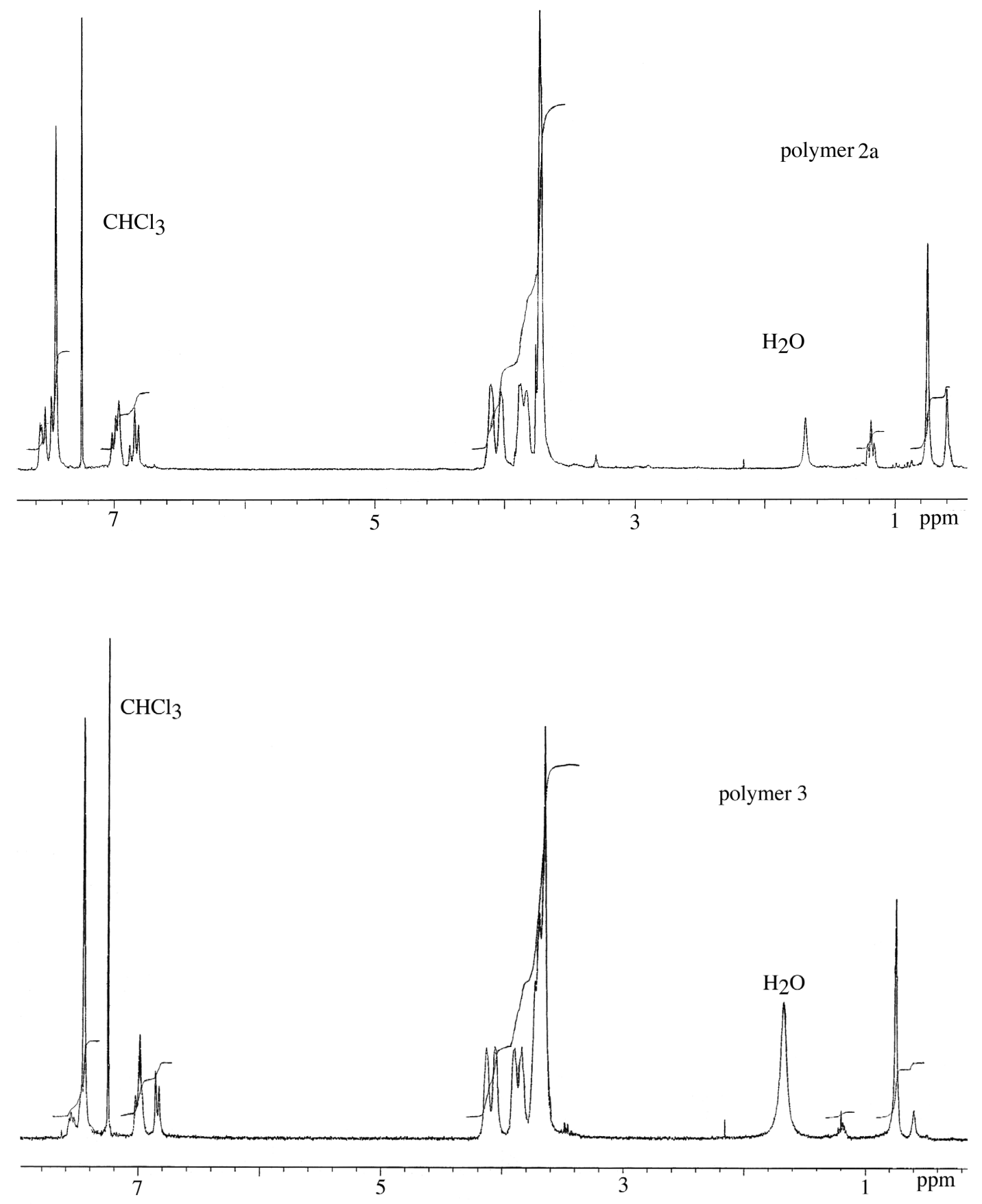


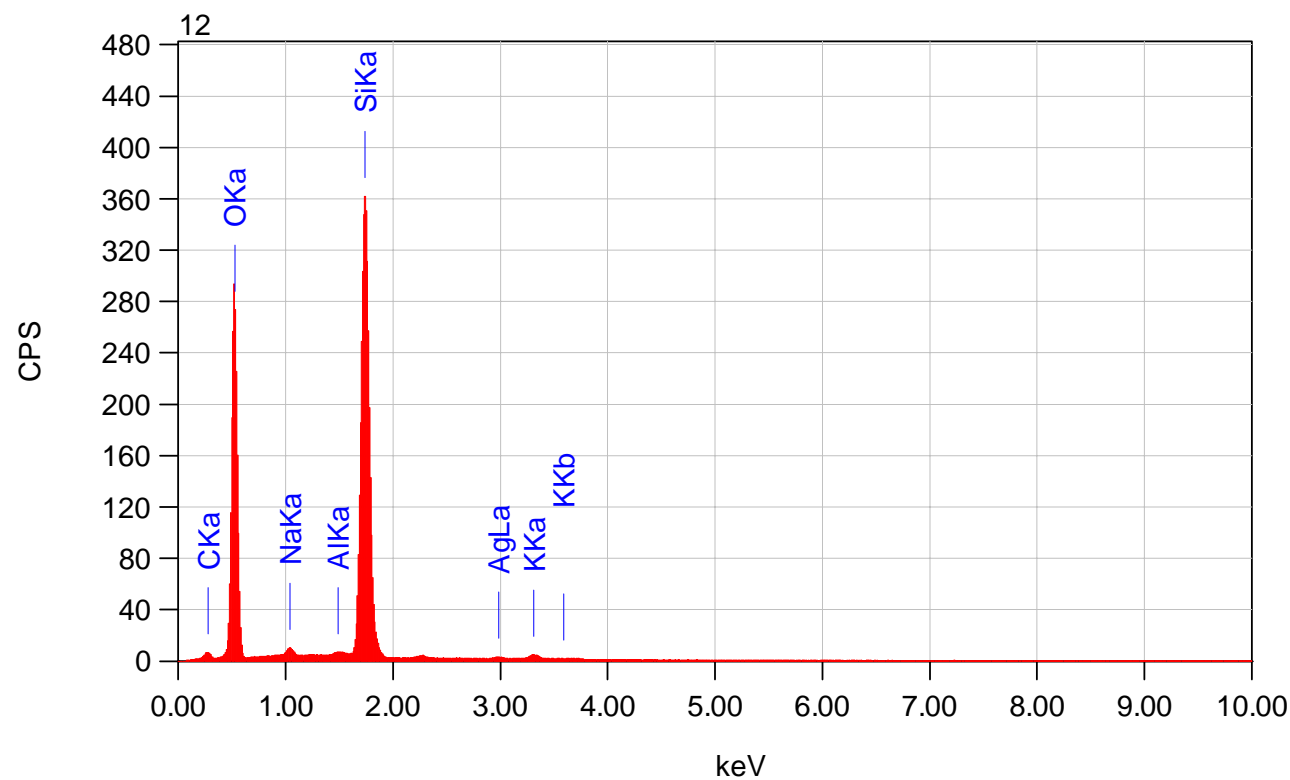

